\title{
SOLUBILIDAD PROTEICA, CONTENIDO DE MIOGLOBINA, COLOR Y PH DE LA CARNE DE POLLO, GALLINA Y CODORNIZ
}

\author{
PROTEIN SOLUBILITY, MYOGLOBIN CONTENT, COLOR AND PH IN CHICKEN, \\ HEN AND QUAIL MEAT
}

\begin{abstract}
Cori, M.E. ${ }^{1 *}$; Michelangeli, C. ${ }^{2}$; De Basilio, V. ${ }^{3}$; Figueroa, R. ${ }^{4}$ y Rivas, N. ${ }^{1}$
${ }^{1}$ Universidad Central de Venezuela. Facultad de Agronomía. Instituto de Química y Tecnología. Maracay. Aragua. Venezuela. *martacori@gmail.com

${ }^{2}$ Universidad Central de Venezuela. Facultad de Ciencias Veterinarias. Centro de Bioquímica Nutricional. ${ }^{3}$ Universidad Central de Venezuela. Facultad de Agronomía. Instituto de Producción Animal.

${ }^{4}$ Universidad Central de Venezuela. Facultad de Agronomía. Instituto de Ingeniería Agrícola.
\end{abstract}

\section{Palabras clave adicionales}

Proteína sarcoplásmica. Proteína miofibrilar. Pechuga. Pierna.

\section{RESUMEN}

Las proteínas de la carne son responsables de diversas características de sus productos derivados. La solubilidad de las proteínas cárnicas puede ser un índice de otras propiedades funcionales importantes para el procesamiento de la carne, como la emulsificación, mientras que el contenido de mioglobina influye en su color. Con el objeto de evaluar la solubilidad de las proteínas sarcoplásmicas y miofibrilares así como el contenido de mioglobina en la carne de aves, se obtuvieron canales de pollo, gallina y codorniz a partir de mataderos comerciales; se aplicó un diseño completamente aleatorizado con arreglo factorial $3 \times 2$, siendo los factores: tipo de ave (pollo, gallina y codorniz) y porción corporal (carne de pechuga y carne de pierna) generándose seis tratamientos, tres repeticiones por tratamiento. Se observó interacción de los factores para: Luminosidad (L), grado de color rojo (a), pH, extracción de proteínas sarcoplásmicas y proteínas miofibrilares. El contenido de mioglobina fue afectado tanto por la porción corporal como por el tipo de ave, siendo superior en la pierna en comparación con la pechuga $(0,99$ y $0,47 \mathrm{mg} / \mathrm{g}$ carne, respectivamente), y siendo la codorniz la que presenta el mayor valor $(1,13 \mathrm{mg} / \mathrm{g})$ y el pollo el menor $(0,37 \mathrm{mg} / \mathrm{g})$. En todos los casos el pH de la carne de pierna fue superior al pH de la pechuga. En la extracción de las proteínas del sarcoplasma hubo una tendencia

\section{AdDitionAl KEYWORDS}

Breast. Leg. Myofibrillar protein. Sarcoplasmic protein.

a obtener un mayor porcentaje de la pechuga, mientras que las proteínas miofibrilares se obtuvieron en mayor proporción en la porción de la pierna. La información generada sobre las características de la carne de estas aves es novedosa en Venezuela y puede contribuir a explicar el comportamiento de estas materias primas durante su procesamiento.

\section{SUMMARY}

The meat proteins are responsible for diverse characteristics of their derived products. The solubility of the meat proteins can be an index of other important functional properties for the meat processing (as the emulsification), while the myoglobin content influences the meat color. In order to evaluate the solubility of the sarcoplasmic and myofibrillar proteins as well as the myoglobin content in poultry meat, there were obtained chicken, hen and quail carcasses from commercial slaughterhouses; it was applied a completely random design with factorial arrangement $3 \times 2$ : type of poultry (chicken, hen and quail) and body portion (breast and leg meat), with six treatments, three repetitions in each treatment. There was found interaction in the factors: lightness (L), redness (a), $\mathrm{pH}$, extractability of sarcoplasmic and myofibrillar proteins. The myoglobin content 
was affected by the body portion and the type of poultry, being higher in the leg than in the breast (0.99 and $0.47 \mathrm{mg} / \mathrm{g}$ meat, respectively), the quail had the highest value $(1.13 \mathrm{mg} / \mathrm{g})$ and the chicken the lowest value $(0.37 \mathrm{mg} / \mathrm{g})$. In all the cases the leg $\mathrm{pH}$ was higher than the breast $\mathrm{pH}$. There was a tendency to obtain a higher extractability of the sarcoplasmic proteins from the breast meat, while the myofibrillar proteins were obtained in a higher proportion from the leg portion. The information generated about the characteristics of these poultry meat is novel in Venezuela and can contribute to explain the behavior of these raw materials during the processing activities.

\section{INTRODUCCIÓN}

La composición del tejido muscular varía, entre otros factores, con la edad, género, especie y estado de nutrición, siendo las proteínas las que constituyen la fracción más importante de la materia seca. Las proteínas del músculo desempeñan un papel fundamental en su función biológica, tanto in vivo como en los procesos postmortem, y se clasifican como sarcoplásmicas, miofibrilares y del estroma (Ponce, 2006).

La carne que es utilizada para la elaboración de productos cárnicos (especialmente la de aves) generalmente es sometida a la congelación en el período previo al procesamiento. A las temperaturas usuales de congelación (de -20 a $-35{ }^{\circ} \mathrm{C}$ ) el $90 \%$ del agua está congelada, lo que hace aumentar 10 veces la concentración de solutos del agua no congelada. En las zonas donde está presente esta solución, se produce una acusada desnaturalización de las proteínas, debido al aumento de la fuerza iónica y a las variaciones del $\mathrm{pH}$. Hay poco cambio en la capacidad de extracción de la actomiosina de la carne sometida a un proceso de congelación rápido y almacenada a $-30^{\circ} \mathrm{C}$, mientras que en la conservada entre $-1,5 \mathrm{y}-20^{\circ} \mathrm{C}$ la actomiosina se hace más difícilmente extraíble (Cheftel et al., 1989).

La principal consecuencia de la desnaturalización de las proteínas es un descenso de su capacidad de retención de agua, lo que durante la descongelación, produce un fuerte exudado que contiene vitaminas, sales minerales y aminoácidos. Cheftel et al. (1989) señalan que el grado de insolubilidad es, probablemente, la medida más práctica de la desnaturalización-agregación proteica, pues las proteínas que están en un estado desnaturalizado, parcialmente agregado, muestran frecuentemente un descenso de la capacidad de gelificación, emulsión o formación de espumas. Esta relación entre la desnaturalización y la insolubilidad proteica, ha permitido los análisis correspondientes en estudios como el de Rathgeber et al. (1999), quienes observaron que las canales de pavos que poseían un proceso glucolítico rápido postmortem tenían un menor índice de extracción de proteínas sarcoplasmáticas y miofibrilares que las que habían sufrido un proceso glucolítico normal, o como en el trabajo de Pietrzak et al. (1997), donde se observó que la carne pálida suave y exudativa (PSE) de la pechuga de los pavos, la cual es poco recomendada para la elaboración de productos cárnicos en los que se requiera una gran capacidad de retención de agua, presentaba un menor índice de miosina solubilizada que la carne normal.

De acuerdo a lo señalado anteriormente, considerando la importancia de la solubilización de las proteínas cárnicas como un índice del estado de su conformación natural, y dada la relación de estos aspectos con propiedades de hidratación de estas proteínas, es pertinente una caracterización de algunas muestras de carne que se comercializan en la región central del país.

Por otro lado, no solamente características como la textura y el rendimiento de los productos cárnicos pueden ser determinados por las proteínas de la carne, también el color de la carne es de gran importancia en todas las etapas de la industria cárnica. Estudios de preferencia de los consumidores hacen énfasis en que el color de la carne es uno de los factores básicos que tiene influencia en la aceptación de la carne fresca 


\section{SOLUBILIDAD PROTEICA Y CONTENIDO DE MIOGLOBINA}

(Rickansrud y Henrickson, 1967), siendo el contenido de la hemoglobina y la mioglobina un factor determinante en su color (Kranen et al., 1999). Ambas hemoproteínas, son del tipo sarcoplásmicas con una conformación globular, solubles en agua y en soluciones salinas diluidas; sin embargo, desde el punto de vista del procesamiento de carnes, el pigmento más importante es la mioglobina, dado que la hemoglobina se elimina durante el desangrado de los animales en el proceso de matanza (Guerrero et al., 2006).

En Venezuela la carne de pollo es la que se suele usar en la elaboración de productos cárnicos provenientes de aves, pero también se suele incorporar la de gallinas de descarte. Por otra parte, aves no tradicionales como la codorniz que se explotan en nuestro país, se conocen muy poco (Cori et al., 2009). Así, es pertinente no solo caracterizar algunas de las propiedades de la carne de codorniz, sino también compararla con la de aves empleadas tradicionalmente, como el pollo, o la gallina, de modo de tener suficiente información para poder tomar decisiones sobre el uso de la carne de las aves mencionadas en la elaboración de productos cárnicos.

Con la finalidad de efectuar una contribución en este sentido, se realizó este trabajo con el objetivo de evaluar el contenido de proteínas miofibrilares y sarcoplásmicas extraíbles, color y contenido de mioglobina en carne de pechugas y piernas de gallina, pollo y codorniz.

\section{MATERIAL Y MÉTODOS}

Las canales de pollo, gallina y codorniz fueron obtenidas a partir de mataderos comerciales, siendo provenientes de aves de la misma edad, y de las mismas granjas. Tanto los pollos (Cobb, machos de 42 días), como las codornices (machos de 45-56 días) y las gallinas (Isa Brown, de descarte, de 70 semanas) fueron beneficiadas mediante aturdimiento eléctrico, degollado, desangrado, escaldado, desplumado, eviscerado, corte de cabeza y patas, pre-enfriamiento, enfriamiento y empacado en bolsas de polietileno.

Las canales de codorniz fueron sometidas a congelación $\left(-18{ }^{\circ} \mathrm{C}\right)$ durante 5 días después del beneficio, mientras que las canales de pollo y gallina fueron conservadas $\mathrm{a}-10^{\circ} \mathrm{C}$ durante 2 días antes de la obtención de las muestras de carne.

La unidad experimental constó de la mezcla de carne de pechuga o de carne de pierna y muslo proveniente de 4 canales de pollo, gallina y codorniz. Se empleó un diseño completamente aleatorizado aplicando un arreglo factorial 3x2, siendo los factores: producto y porción corporal.

-Producto (tres tipos): canal de pollo, canal de gallina y canal de codorniz.

-Porción corporal (dos porciones): carne de pechuga (músculo pectoral torácico y al músculo supracoracoideo, Shively, 1987), y carne de pierna, muslo+pierna, (músculos que recubren el fémur, tibia y peroné del ave, Norma Venezolana COVENIN 2407-86) (Comisión Venezolana de Normas Industriales, 1986).

Cada tratamiento fue evaluado utilizando tres repeticiones, para un total de 18 evaluaciones, requiriéndose 12 canales de cada una de las aves.

La carne de la pechuga y pierna se separó manualmente, fue molida (procesador manual Oster de 250 vatios) e inmediatamente evaluada para el color y el $\mathrm{pH}$. El resto se congeló $\left(-18^{\circ} \mathrm{C}\right)$ hasta el momento de los análisis.

Se analizaron por duplicado:

Color, a través de la evaluación de la Luminosidad (L), grado de rojo o verde (a) y grado de amarillo o azul de la carne (b), de la carne molida según Barbut (1993), empleando un colorímetro Master color data asistido por computadora (Hunterlab Universal Software).

$p H$, mediante medición directa en la carne molida con un analizador marca Hanna Modelo HI 8424 (Barbut, 1993 y Mc Curdy et al., 1996).

Capacidad de extracción de las protei- 
nas sarcoplásmicas y miofibrilares, según el método usado por Molette et al. (2003): se homogeneizó un gramo de carne molida en $20 \mathrm{~mL}$ de buffer de baja fuerza iónica (fosfato de potasio 0,05 M, $\mathrm{NaN}_{3} 1 \mathrm{mM}$, EDTA $2 \mathrm{mM}$, $\mathrm{pH} 7,3$, a $2{ }^{\circ} \mathrm{C}$ ) por 10 segundos, usando una licuadora manual (marca Braun, MR 5550 CA de 400 Watt), y se colocó en hielo por 30 minutos. Se tomaron $5 \mathrm{~mL}$ de esta suspensión y se centrifugó a 17500 x g por 15 minutos a $2{ }^{\circ} \mathrm{C}$ en una Ultracentrífuga Marca Beckman, modelo L8-80M, usando un rotor tipo $80 \mathrm{TI}$. Se tomaron 2,5 mL del sobrenadante (extracto de proteína sarcoplásmica) con una inyectadora, descartando el sobrenadante remanente. El residuo se resuspendió en $5 \mathrm{~mL}$ adicionales del buffer de baja fuerza iónica, homogeneizando y centrifugando como se indicó anteriormente. Se descartó el sobrenadante y la operación se repitió utilizando un buffer de alta fuerza iónica (cloruro de potasio 0,55 M, fosfato de potasio $0,05 \mathrm{M}, \mathrm{NaN}_{3} 1 \mathrm{mM}$, EDTA 2 mM, pH 7,3, a $2{ }^{\circ} \mathrm{C}$ ). Después de la centrifugación se tomaron $2,5 \mathrm{~mL}$ del sobrenadante (extracto de proteína miofibrilar).

Contenido de proteína. Las proteínas miofibrilares y sarcoplásmicas (proteína verdadera) se determinaron en los respectivos extractos utilizando el método de Bradford (1976). El contenido de estas proteínas se expresó de manera porcentual con respecto al total de la proteína de la carne (proteína cruda), la cual se determinó según la Norma COVENIN 1218-80 (Comisión Venezolana de Normas Industriales, 1980).

Contenido de mioglobina, según el método de Van Laack et al. (1996). Se homogeneizaron 2,5 g de carne molida en $25 \mathrm{~mL}$ buffer fosfato de sodio 0,04 M, pH 6,8 usando para ello una licuadora manual, marca Braun, MR 5550 CA de 400 Watt. Una alícuota de $5 \mathrm{~mL}$ de la mezcla se centrifugó por 30 minutos a 45000 x g en una Ultracentrífuga Marca Beckman, modelo L8-80M, usando un rotor tipo $80 \mathrm{TI}$, el sobrenadante se filtró con papel de filtro Whatman $\mathrm{N}^{\circ} 1$ (Trout, 1989) y se determinó la absorbancia a 525 y
730 nm con un espectrofotómetro Marca Beckman, modelo DU 650. Para la determinación de la concentración de mioglobina (mg/g) se asumió su masa molecular de 17500 Dalton, y el coeficiente de extinción molar de $7600 \mathrm{Mxcm}^{-1}$, tal como se indica en la siguiente fórmula: $\left(A_{525}-1,73 A_{730}\right) x$ $\{[($ Peso muestra $x \% H u m e d a d) / 100+25] /$ Peso muestra $\}$ x (17500/7600). Para la aplicación de esta fórmula se requiere la determinación de humedad de las muestras, que en el caso del presente trabajo fue determinada según el método descrito en Official Methods of Analysis (AOAC, 1997) bajo el número 950.46.

Análisis estadístico. Una vez probado el cumplimiento de los supuestos del Análisis de la Varianza, se procedió a efectuar el ANAVAR para cada una de las variables evaluadas, y en aquellos casos donde se encontraron diferencias significativas se efectuó la Prueba de Medias de Tukey empleando un nivel de significación del $5 \%$.

Los análisis estadísticos se llevaron a cabo a través del programa Statistix 8.0.

\section{RESULTADOSYDISCUSIÓN}

En la tabla I se presenta el efecto de los factores tipo de ave y porción corporal sobre el grado de color amarillo o azul de la carne (b) y el contenido de mioglobina, que fueron las únicas variables de las evaluadas donde no se presentó interacción entre los factores. En el caso del grado de color amarillo (b) solo hay efecto del tipo de ave, observándose que la carne de gallina es significativamente más amarilla que la de codorniz.

Con respecto al grado de color amarillo (b) de la carne de codorniz, los valores del presente estudio son ligeramente superiores a los encontrados por Cori et al. (2011) para carne de codornices macho de 42-45 días $(7,16)$ y de $56-59$ días $(6,35)$, pero inferiores a los reportados por Remignon et al. (1998) para pechuga de codornices macho sometidas a estrés $(12,79)$. 


\section{SOLUBILIDAD PROTEICA Y CONTENIDO DE MIOGLOBINA}

Tabla I. Efecto del tipo $(T)$ de ave y de la porción corporal $(P)$ sobre la solubilidad de proteínas miofibrilares y sarcoplásmicas, el contenido de mioglobina, color y pH de la carne. (Effect of the type $(T)$ of bird and the body portion $(P)$ on the solubility of myofibrillar and sarcoplasmic proteins, myoglobin content, color and $\mathrm{pH}$ of meat).

\begin{tabular}{|c|c|c|c|c|c|c|c|}
\hline & $\begin{array}{r}\text { Prot } \\
\text { Sarcoplásmica* }\end{array}$ & $\begin{array}{l}\text { eína } \\
\text { Miofibrilar* }\end{array}$ & Mioglobina** & L & $\mathrm{a}$ & b & $\mathrm{pH}$ \\
\hline \multicolumn{8}{|l|}{ Tipo (T) } \\
\hline Pollo & $24,29 \pm 8,54$ & $2,49 \pm 1,03$ & $0,37 \pm 0,19^{b}$ & $53,69 \pm 3,17$ & $2,24 \pm 0,52$ & $10,27 \pm 1,01^{\mathrm{ab}}$ & $6,17 \pm 0,16$ \\
\hline Gallina & $17,76 \pm 1,89$ & $2,11 \pm 0,50$ & $0,69 \pm 0,34^{\mathrm{ab}}$ & $52,27 \pm 5,13$ & $4,28 \pm 1,62$ & $10,89 \pm 0,61^{a}$ & $5,85 \pm 0,16$ \\
\hline Codorniz & $15,34 \pm 3,49$ & $2,08 \pm 0,45$ & $1,13 \pm 0,50^{\mathrm{a}}$ & $44,36 \pm 2,10$ & $6,29 \pm 0,63$ & $9,19 \pm 0,33^{b}$ & $6,36 \pm 0,34$ \\
\hline $\mathrm{p}$ & 0,0003 & 0,0923 & 0,0145 & 0,0000 & 0,0000 & 0,0057 & 0,0000 \\
\hline \multicolumn{8}{|l|}{ Porción (P) } \\
\hline Pechuga & $21,96 \pm 8,30$ & $1,79 \pm 0,30$ & $0,47 \pm 0,36^{b}$ & $51,42 \pm 6,58$ & $3,61 \pm 1,77$ & $10,32 \pm 0,98^{a}$ & $5,93 \pm 0,17$ \\
\hline Pierna & $16,30 \pm 2,76$ & $2,66 \pm 0,76$ & $0,99 \pm 0,55^{a}$ & $48,79 \pm 4,03$ & $4,94 \pm 2,02$ & $9,92 \pm 0,99^{a}$ & $6,32 \pm 0,30$ \\
\hline $\mathrm{p}$ & 0,0008 & 0,0002 & 0,0126 & 0,0180 & 0,0008 & 0,2544 & 0,0000 \\
\hline$T \times P$ & 0,0007 & 0,0040 & n.s. & 0,0013 & 0,0138 & n.s. & 0,0005 \\
\hline
\end{tabular}

*Porcentaje de la proteína bruta; **mg/g de carne.

Los resultados corresponden a media \pm desviación estándar.

Para las variables donde no se presenta interacción: en cada columna, valores seguidos de letras distintas indican diferencias significativas $(p \leq 0,05)$ por la prueba de medias de Tukey. n.s. $=p>0,05$.

En el pollo, los valores de este parámetro encontrados son inferiores a los reportados por Lambooij et al. (1999) de 19,10, superiores a los señalados por Bianchi et al. (2006) de 3,61, por McNeal y Fletcher (2003) de 7,4 y muy similares al encontrado por Qiao et al.(2002) de 9,05.

Las diferencias encontradas en el color de la carne con respecto a otros trabajos podría deberse, tal y como lo señalan Qiao et al. (2002), a diferencias de manejo, dieta y genética de las aves, además de las características del colorímetro empleado.

En relación al contenido de mioglobina, en el tabla I se aprecia que es afectado por el tipo de ave, siendo la codorniz la que presenta el mayor valor $(1,13 \mathrm{mg} / \mathrm{g})$ y el pollo el menor $(0,37 \mathrm{mg} / \mathrm{g})$. La porción corporal también es determinante, siendo el mayor contenido el de la pierna $(0,99 \mathrm{mg} / \mathrm{g})$ en comparación con la pechuga $(0,47 \mathrm{mg} / \mathrm{g})$. Estos valores pueden explicar que la carne de codorniz (pechuga y pierna) sea la que presenta menores valores de luminosidad (figura 1), y un mayor valor para el color rojo (a), según se aprecia en la tabla I.

En la figura 1 se observa que la pechuga

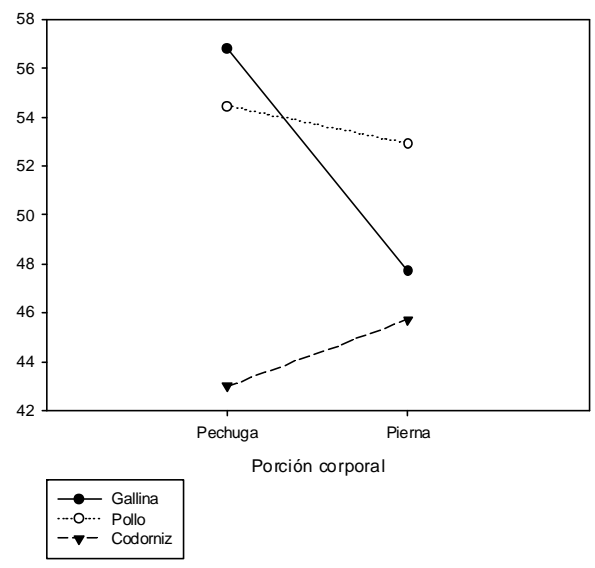

Figura 1. Interacción del tipo de ave y la porción corporal en el valor de L. (Interaction of the type of bird and the body portion on the $L$ value). 


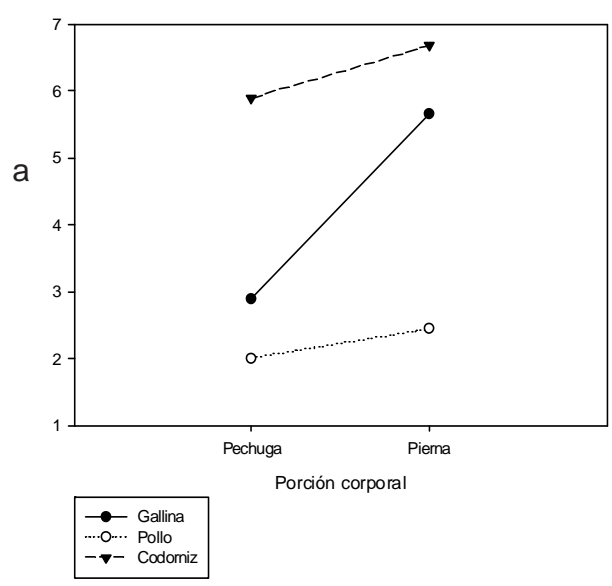

Figura 2. Interacción del tipo de ave y la porción corporal en el valor de a. (Interaction of the type of bird and the body portion on the a value).

de codorniz es más oscura que la de pollo y gallina. En el caso de la codorniz y el pollo son muy cercanos los valores de claridad entre sus respectivas pechugas y piernas, mientras que en la gallina la pechuga es mucho más clara que la pierna.

En la figura 2 se aprecia que la pechuga de codorniz es más roja que la de gallina y pollo. En cuanto a la pierna, la carne de codorniz tiene un valor muy similar al de gallina, siendo ambas carnes más rojas que la del pollo. Para las tres aves estudiadas, la carne de la pierna es más roja que la de la pechuga; en el caso del pollo y codorniz, la magnitud de la diferencia entre los valores de a para la pechuga y la pierna es pequeña, mientras que en el caso de la gallina, se evidencia que la pierna es mucho más roja que la pechuga.

El valor encontrado para L en la codorniz, es similar a los reportados por Cori et al. (2011) para carne de codornices macho de 42-45 días $(42,6)$ y ligeramente superior a los de 56-59 días de edad $(39,57)$. El valor reportado por Remignon et al. (1998) para pechuga de codornices macho sometidas a estrés $(45,01)$ es similar al obtenido para la pechu- ga de codorniz en el presente trabajo $(42,98)$.

Los valores de luminosidad para la carne de pollo de este estudio, son ligeramente inferiores a lo encontrado por Lambooij et al. (1999) de 58,84, 24 horas postmortem para pechuga de pollos de 5 a 6 semanas de edad, sometidos a aturdimiento eléctrico durante el beneficio, y al de Qiao et al.(2002) de 57,83 para pechugas de pollo, similares a lo reportado por Bianchi et al. (2006) de 52,63, y por McNeal y Fletcher (2003) de 51.

Los valores de a encontrados en el presente trabajo para la codorniz son muy similares a los obtenidos por Cori et al. (2011) para carne de codornices macho de 42-45 días $(6,27)$ y de 56-59 días $(6,72)$, y al reportado por Remignon et al. (1998) para pechuga de codornices macho sometidas a estrés $(6,64)$. En pollos, los valores obtenidos en este estudio son similares a los encontrados por McNeal y Fletcher (2003) de 2,5 y por Bianchi et al. (2006) de 3,19, mientras que son marcadamente inferiores a los reportados por Lambooij et al. (1999) de 6,63 y por Qiao et al. (2002) de 5,01.

Con respecto al $\mathrm{pH}$, en el pollo y la gallina la diferencia entre los valores de la pierna y la pechuga es la misma, pero en el caso de la codorniz es mucho mayor esta diferencia (figura 3 ).

En todos los casos el pH de la carne de pierna es superior al $\mathrm{pH}$ de la pechuga, lo cual puede ser debido en parte a la restricción del movimiento de las piernas de las aves asociado a los ganchos donde se ubican los animales en el matadero. Lambooij et al. (1999) encontraron al beneficiar pollos bajo dos sistemas de restricción (el cono que restringe el movimiento de las alas, y los ganchos que restringen el movimiento de las piernas) que el menor $\mathrm{pH}$ en un determinado músculo se encontró con el sistema de sujeción que permitió mayor movimiento premortem, siendo muy evidente durante las primeras 2 horas después del sacrificio, lo que permite deducir que sería por el más pronto inicio de la glucólisis y con ello, de la acumulación de ácido láctico. De hecho, 
estos autores encontraron a los 60 minutos postmortem un $\mathrm{pH}$ de 6,22 para la pechuga y 6,25 para el muslo del pollo sujeto con ganchos, valores que no presentan una marcada diferencia en sus magnitudes, pero que ilustran la tendencia anteriormente señalada. El trabajo de Genchev et al. (2005) con codornices, evidencia mejor los señalamientos anteriores, ya que reportan a 24 horas postmortem (en refrigeración) un $\mathrm{pH}$ de 5,61 para la pechuga y 6,63 para el muslo. Dado que en nuestro país los mataderos comerciales de pollo y gallina emplean el sistema de ganchos, método que se utilizó igualmente para el beneficio de las codornices del ensayo, es lógico observar los menores valores correspondientes a la pechuga de las aves.

Sin embargo, las determinaciones de Kiessling (1977), de los cocientes de la actividad de la citocromo-oxidasa y de la lactato deshidrogenasa en pollo, gallina y codorniz, mostraron menores valores para las pechugas de pollo y gallina $(0,2$ y 0,2$)$ en comparación con carne de sus piernas $(0,9$ y 1,4), indicando un predominio del metabolismo oxidativo sobre el glucolítico en ese músculo, todo lo cual explicaría los mayores

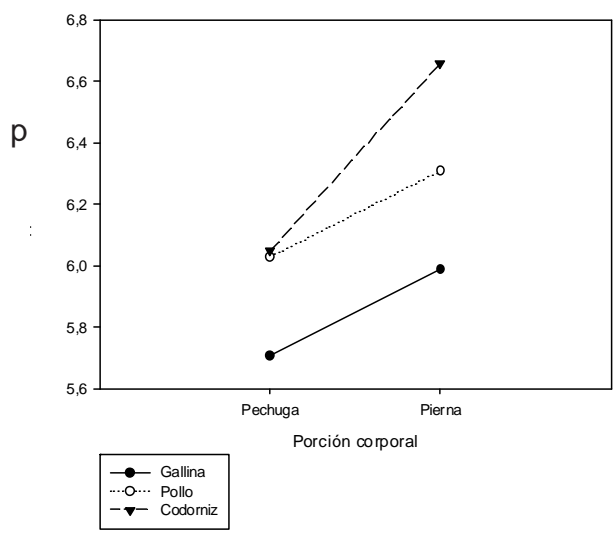

Figura 3. Interacción del tipo de ave y la porción corporal en el $\mathrm{pH}$. (Interaction of the type of bird and the body portion on the $\mathrm{pH}$ ). valores del pH en la carne de las piernas en nuestro estudio. Este autor señala un cociente de 2,4 en piernas de codorniz, lo cual explicaría el mayor valor de $\mathrm{pH}$ reportado en este trabajo (figura 3) para la codorniz en comparación con las otras aves. En el caso de la pechuga, este autor encontró un menor cociente de actividad enzimática $(3,6)$ lo cual sugiere una mayor actividad aeróbica en este músculo, esperándose entonces un mayor valor de $\mathrm{pH}$ que la pierna, lo cual no se evidencia en este estudio. Este análisis permite apreciar que trabajos como el de Kiessling (1977) pueden ser muy útiles como una guía para dar algunas explicaciones de los fenómenos observados, pero no siempre tienen todas las respuestas, y las razones pueden estar en el hecho de que la codorniz, un animal tradicionalmente muy sensible al estrés o de temperamento fácilmente excitable, es muy propensa a consumir el glucógeno muscular disponible en las piernas, en las horas antemortem, por los movimientos de desplazamiento en la jaula, resultando en valores de $\mathrm{pH}$ final de su carne mucho más altos, mientras que probablemente haya tenido aún glucógeno en los músculos de la pechuga, y debido al intenso aleteo de estos animales una vez que son colocados en los ganchos para el aturdimiento, es probable que haya ocurrido un rápido descenso del $\mathrm{pH}$ postmortem, resultando en un valor inferior al de la pierna. Por otro lado, no se tiene la información de, a cuántas horas postmortem Kiessling (1977) hizo los análisis de la actividad enzimática, ya que en el período prerigor o rigor mortis, el $\mathrm{pH}$ pudo haber sido diferente al encontrado en el presente estudio, variable que fue evaluada luego de más de 48 h postmortem, habiendo sido las canales sometidas a temperaturas de congelación una vez que llegaron al rigor mortis.

El valor del pH encontrado para la codorniz $(6,36)$ es muy similar al reportado por Cori et al. (2011) para carne de codornices macho de 42-45 días $(6,21)$ y de 56-59 días $(6,34)$, al ser evaluada dicha variable 24 
horas postmortem en refrigeración, mientras que en la figura 3 se evidencia en primer lugar un menor valor del $\mathrm{pH}$ de la pechuga de codorniz en comparación con el reportado por Remignon et al. (1998) de 5,86, y por otro lado se observa la misma tendencia encontrada por Genchev et al. (2005) relacionada con un mayor valor de $\mathrm{pH}$ en la pierna en comparación con la pechuga.

En cuanto a la carne de pollo, el valor de $\mathrm{pH}$ para la pechuga $(6,03)$ es muy similar al que señalan Qiao et al. (2002) para pechuga de pollo $(5,96)$, pero ligeramente superior al encontrado por McNeal y Fletcher (2003) de 5,83 .

Es interesante señalar (figuras 1 y 3 ) una asociación entre menores valores de $\mathrm{pH}$ y una mayor claridad (L). Este hecho lo reporta Barbut (1993) para la pechuga de pavos de 18 semanas de edad, encontrando una alta correlación negativa entre el $\mathrm{pH}$ y el valor de $L^{*}$ de la pechuga intacta; igualmente Qiao et al. (2002) observaron que las pechugas de pollo con los valores más altos de $\mathrm{pH}(6,23)$ eran las más oscuras, las de menor pH $(5,82)$ eran las más claras y las consideradas normales tenían un $\mathrm{pH}$ intermedio (5,96).

En relación al contenido de proteínas sarcoplasmáticas y miofibrilares, se encontró interacción de los factores Tipo y Porción, lo cual se evidencia en las figuras 4 y 5 .

La extracción de las proteínas sarcoplásmicas de la pechuga del pollo (31,93\%) supera a la de la pechuga de la codorniz (15,42\%) y gallina $(18,53 \%)$, mientras que no hay diferencias en el porcentaje de extracción de proteína de la pierna de las tres aves, cuyos valores oscilan entre 15,26 y $17,00 \%$ (figura 4 ).

En el caso de las proteínas miofibrilares (figura 5) se observa una tendencia opuesta a la de las proteínas del sarcoplasma, ya que los valores de extracción de la pierna del pollo (3,40\%) superan los valores de la pierna de codorniz (2,18\%) y de gallina (2,39\%), mientras que no hay diferencias importantes entre la proteína extraída de la pechuga de las tres aves, cuyos valores se encuentran entre 1,59 y 1,98\%.

A partir del análisis de las figuras 4 y 5 , se puede concluir que si se trata de la capacidad de extracción de las proteínas del sarcoplasma hay una tendencia a que se obtenga un mayor porcentaje de la porción de la pechuga, pero es solo en el caso del pollo que esta superioridad se hace más evidente. Para el caso de la capacidad de extracción de las proteínas miofibrilares, se tienden a extraer más de la porción de la pierna, siendo igualmente para el caso del pollo que se pone de manifiesto de forma más acentuada esta diferencia.

Las proteínas miofibrilares son muy importantes, porque tienen un papel fundamental en la formación de geles, son responsables de la capacidad de retención de agua de la carne, de las propiedades emulsificantes y de la terneza de la carne, (Kuhn y Soares, 2002) por lo que sería aparentemente preferible el empleo de carne de la pierna para la elaboración de

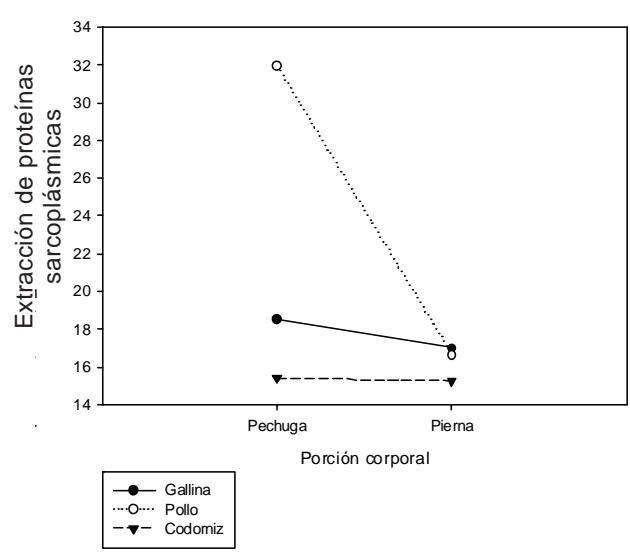

Figura 4. Interacción del tipo de ave y la porción corporal en la solubilidad de proteínas sarcoplásmicas (g/100 g proteína bruta). (Interaction of the type of bird and the body portion in the solubility of sarcoplasmic proteins ( $\mathrm{g} / 100 \mathrm{~g}$ crude protein)). 
productos como salchichas.

Desde el punto de vista tecnológico sería indiferente el empleo de pechuga de pollo, gallina o codorniz, pero si se debiera elegir entre la carne de pierna de los tres tipos de ave, la de pollo sería la opción más lógica (figura 5).

Existe cierta dificultad al efectuar comparaciones directas con otros trabajos que han evaluado la capacidad de extracción de proteínas sarcoplásmicas y miofibrilares, debido a la variedad de métodos existentes para medir estas variables, aspecto que también señalan Molette et al. (2003), sin embargo a continuación se presentan algunas reflexiones basadas en la bibliografía disponible donde se empleó una metodología similar a la usada en el presente estudio.

El valor obtenido en este trabajo para la extracción de proteína sarcoplásmica de la pechuga de pollo (31,93 \%) es similar al encontrado por Rathgeber et al. (1999) para pechuga de pavo producto de una glucólisis postmortem normal (29,9\%) pero es ligeramente superior al valor de la pechuga de dicha ave después de una glucólisis rápida (27,7 \%). Estos valores, a su vez, son sustancialmente mayores a los de pechuga de gallina $(18,53 \%)$ y pechuga de codorniz (15,42\%) del presente trabajo.

En el caso de Molette et al. (2003) se encontró en pechugas de pavo un $27 \%$ de proteínas sarcoplásmicas (teniendo igualmente como base la proteína cruda) después de un almacenamiento de 24 horas a $4{ }^{\circ} \mathrm{C}$, disminuyendo este valor a $24,9 \%$ luego de 9 días de almacenamiento a la misma temperatura. Los valores obtenidos en el presente trabajo para la pechuga de las aves son inferiores a los señalados anteriormente, a excepción del correspondiente a la pechuga de pollo.

Los valores bajos encontrados en el presente estudio con respecto a otros trabajos, pueden ser debidos a la naturaleza de las proteínas de cada tipo de ave, o bien por las características del proceso glucolítico postmortem desarrollado, pues tal y como lo señala Offer (1991) citado por Alvarado y Sams (2004) el rápido descenso del pH combinado con la alta temperatura de la canal pueden originar la desnaturalización de ciertas proteínas, fenómeno que ilustran Rathgeber et al. (1999) según los valores antes presentados. Van Laack et al. (2000) encontraron una mayor solubilidad de las proteínas del sarcoplasma en pechuga de pollo de color normal (50 mg/g) en comparación con pechuga de pollo pálida (44mg/g), indicando que este comportamiento indicaba una mayor desnaturalización proteica en las últimas, donde se observó un $\mathrm{pH}$ inferior al de las primeras $(5,70$ vs 5,96$)$.

En relación a las proteínas miofibrilares los valores encontrados en este estudio son inferiores a los presentados por Rathgeber et al. (1999) para pechuga de pavo producto de una glucólisis postmortem normal (14,6 \%) y una glucólisis rápida (9,7\%). Molette et al. (2003) encontraron un aumento en la extracción de las proteínas miofibrilares de la pechuga de pavo durante el tiempo de almacenamiento en refrigeración $\left(4{ }^{\circ} \mathrm{C}\right)$, comportamiento

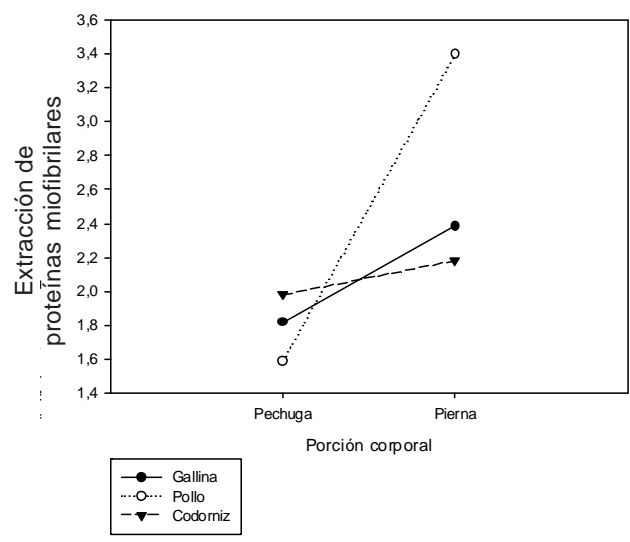

Figura 5. Interacción del tipo de ave y la porción corporal en la solubilidad de proteínas miofibrilares ( $\mathrm{g} / 100 \mathrm{~g}$ proteína bruta). (Interaction of the type of bird and the body portion in the solubility of myofibrillar proteins ( $g /$ $100 \mathrm{~g}$ crude protein)). 
contrario a lo hallado por estos mismos investigadores en las proteínas sarcoplásmicas, ya que el valor pasó de 8,6 \% (6 horas postmortem) a 18,2 \% (9 días), cifras evidentemente superiores a las del presente trabajo (figura 5). Nuevamente se observan valores bajos encontrados en el presente estudio con respecto a otros trabajos, que pueden ser por un lado debidos a razones determinadas por la naturaleza de las proteínas de cada tipo de ave, aspecto que confirman Rathgeber et al. (1999) al encontrar un comportamiento en la carne de pechuga de pavo diferente a la señalada en literatura para la carne de cerdo. También pueden ser debidas a las características del proceso glucolítico postmortem que sufrieron los animales y que ya fue señalado para las proteínas sarcoplásmicas, fenómeno que ilustran Rathgeber et al. (1999).

\section{CONCLUSIONES}

El contenido de mioglobina es superior en la carne de pierna en comparación con la de pechuga, y la carne de codorniz presenta el mayor contenido de mioglobina y el pollo el menor índice de esta proteína, todo lo cual puede debe ser considerado por los fabricantes de productos cárnicos, ya que po-

\section{BIBLIOGRAFÍA}

Alvarado, C. and Sams, A. 2004. Turkey carcass chilling and protein denaturation in the development of pale, soft, and exudative meat. Poultry Sci, 83: 1039-1046.

AOAC. 1997. Method 950.46. In: Official methods of analysis. $16^{\text {th }}$ ed. $3^{\text {rd }}$ revision. AOAC. International. Gaithersburg, MD.

Barbut, S. 1993. Color measurements for evaluating the pale soft exudative (PSE) occurrence in turkey meat. Food Res Int, 26: 39-43.

Bianchi, M.; Petracci, M. and Cavani, C. 2006. The influence of genotype, market live weight, transportation, and holding conditions prior to slaughter on broiler breast meat color. Poultry Sci, 85: 123-128.

Bradford, M. 1976. A rapid and sensitive method drían obtener productos más oscuros o más rojos si es el caso, dependiendo de la materia prima utilizada, con un uso nulo o mínimo de colorantes en forma de aditivos.

Hay mayor extracción de proteínas del sarcoplasma en la carne de pechuga, y mayor extracción de proteínas miofibrilares en la de pierna.

Desde el punto de vista tecnológico, y considerando la extracción de las distintas fracciones proteicas, podría ser indiferente el empleo de pechuga de pollo, gallina o codorniz, pero si la carne a usar es de pierna, la de pollo sería la opción más indicada para la elaboración de productos cárnicos en los que se requiera una alta participación de las proteínas miofibrilares, conocidas por su gran capacidad emulsificante, entre otras propiedades tecnológicas importantes.

\section{AGRADECIMIENTOS}

Los autores desean agradecer al $\mathrm{CDCH}$ de la UCV por el financiamiento de este trabajo a través de los proyectos PG 01-006536-2006, y a todo el personal del Centro de Bioquímica Nutricional de la Facultad de Ciencias Veterinarias de la Universidad Central de Venezuela por el apoyo técnico prestado.

for the quantitation of microgram quantities of protein utilizing the principle of protein-dye binding. Anal Biochem, 72: 248-254.

Cheftel, J.; Cuq, J. y Lorient, D. 1989. Proteínas alimentarias. Editorial Acribia. España. 346 pp. Comisión Venezolana de Normas Industriales (COVENIN). 1980. 1218-80. Carne y productos cárnicos. Determinación de nitrógeno. Primera Revisión. Ministerio de Fomento. Publicaciones de Fondonorma. Caracas-Venezuela. 12 pp.

Comisión Venezolana de Normas Industriales (COVENIN). 1986. 2407-86. Aves. Definiciones e identificación de las piezas de una canal. Publicaciones de Fondonorma. Caracas, Venezuela. 4 pp.

Cori, M.; De Basilio, V.; Figueroa, R.; Michelangeli,

Archivos de zootecnia vol. 63, núm. 241, p. 142. 


\section{SOLUBILIDAD PROTEICA Y CONTENIDO DE MIOGLOBINA}

C.; Galíndez, R. y García, J. 2009. Efecto de la edad de la codorniz (Coturnix coturnix japonica) y del aturdimiento eléctrico al momento del beneficio sobre las características de la canal. Zoot Trop, 27: 175-185.

Cori, M.; De Basilio, V.; Figueroa, R.; Michelangeli, C. y Galíndez, R. 2011. Efecto de la edad de la codorniz (Coturnix coturnix japonica) y del aturdimiento eléctrico al momento del beneficio sobre la composición química, color y propiedades funcionales de la carne. Rev Fac Agron (UCV), 37: 105-115.

Genchev, A.; Ribarski, S.; Afanasjev, G. and Blohin, G. 2005. Fattening capacities and meat quality of japanese quails of faraón and white english breeds. J Cent Europ Agric, 6: 495-500.

Guerrero, I.; López, E. y Armenta, R. 2006. Cap 7: Pigmentos. In: Badui, S. (Ed.). Química de los alimentos. $4^{\mathrm{a}}$ ed. Pearson Educación de México, S.A. de C.V. México. pp. 432-434.

Khun, C. e Soares, G. 2002. Proteases e inibidores no processamento de surimi. Rev Bras Agroc, 8: 5-11.

Kiessling, K. 1977. Muscle structure and function in the goose, quail, pheasant, guinea hen and chicken. Comp Biochem Phys, 57B: 287-292.

Kranen, R.; Van Kuppevelt, T.; Goedhart, H.; Veerkamp, C.; Lambió, E. and Veerkamp, J. 1999. Hemoglobin and myoglobin content in muscles of broiler chickens. Poultry Sci, 78: 467-476.

Lambooij, E.; Pieterse, C.; Hillebrand, S. and Dijksterrhuis, G. 1999. The effects of captive bolt and electrical stunning and restraining methods on broiler meat quality. Poultry Sci, 78: 600-607.

McCurdy, R.; Barbut, S. and Quinton, M. 1996. Seasonal effect on pale soft exudative (PSE) occurrence in young turkey breast meat. Food Res Int, 29: 363-366.

McNeal, W. and Fletcher, D. 2003. Effects of high frecuency electrical stunning and decapitation on early rigor development and meat quality of broiler breast meat. Poultry Sci, 82: 13521355.

Molette, C.; Rémignon, H. and Babilé, R. 2003.
Maintaining muscles at a high post-mortem temperature induces PSE-like meat in turkey. Meat Sci, 63: 525-532.

Offer, G. 1991. Modeling of the formation of pale, soft, and exudative meat: Effects of chilling regime and rate and extent of glycolysis. Meat Sci, 30: 157-184.

Pietrzak, M.; Greaser, M. and Sosnicki, A. 1997. Effect of rapid rigor mortis processes on protein functionality in Pectoralis major muscle of domestic turkeys. J Food Sci, 75: 2106-2116.

Ponce, E. 2006. Cap 4. Cambios bioquímicos pre y postmortem. In: Hui ,Y., Guerrero, I. y Rosmini, M. (Eds.). Ciencia y Tecnología de carnes. Noriega Editores. Limusa. 112. pp.

Qiao, M.; Fletcher, D.; Northcutt, J. and Smith, D. 2002. The relationship between raw broiler breast meat color and composition. Poultry Sci, 81: 424-427.

Rathgeber, B.; Boles, J. and Shand, P. 1999. Rapid postmortem $\mathrm{pH}$ decline and delayed chilling reduce quality of turkey breast meat. Poultry Sci, 78: 477-484.

Remignon, H.; Mills, A.; Guemene, D.; Desrosiers V.; Garreau-Mills, M.; Marche, M. and Marche, G. 1998. Meat quality traits and muscle chracteristics in high or low fear lines of Japanese quails (Coturnix japonica) subjected to acute stress. Brit Poultry Sci, 39: 372-378.

Rickansrud, D. and Henrickson, R. 1967. Total pigments and myoglobin concentration in four bovine muscles. J Food Sci, 32: 57-61.

Shively, M. 1987. Anatomía Veterinaria Básica, Comparativa y Clínica. Editorial El Manual Moderno, S.A. de C.V. México. 322 pp.

Trout, G. 1989. Variation in myoglobin denaturation and color of cooked beef, pork and turkey meat as influenced by $\mathrm{pH}$, sodium chloride, sodium tripolyphosphate, and cooking temperature. J Food Sci, 54: 536-540

Van Laack, R.; Berry, B. and Solomon, M. 1996. Variations in internal color of cooked beef patties. J Food Sci, 61: 410-414.

Van Laack, R.; Liu, C.; Smith, M. and Loveday, H. 2000. Characteristics of pale, soft, exudative broiler breast meat. Poultry Sci, 79: 1057-1061. 